\title{
STUDYING THE EVOLUTION AND THE MAGNETIC RESONANCE FINDINGS OF REVERSIBLE POSTERIOR LEUKOENCEPHALOPATHY IN CHILDREN
}

\author{
José Roberto Ferraz-Filho', José Alves Rocha-Filho², Tatiana Fantin Bichuette², \\ Regina Celia Ajeje P. de Albuquerque ${ }^{3}$, Rafael Angelo Sanchez ${ }^{1}$, Antonio Soares Souza ${ }^{4}$
}

\begin{abstract}
Purpose: To describe the evolution and the magnetic resonance imaging (MRI) findings of the reversible posterior leukoencephalopathy (RLPS) in children. Method: Nine children with neurologic symptoms and sudden increase of the arterial pressure were studied by brain MRI. Results: All children evaluated had lesions seen on FLAIR-weighted images of the parietal-occipital regions. Other regions were also involved. Four patients presented restriction on diffusion-weighted images and only two with reduction of the apparent diffusion coefficient (ADC), whitch evolved with neurologic sequels and persistence of the lesions on the control examination. The other patients had complete regression of the lesions after therapy. Conclusion: MRI is important to suggest the diagnosis of RPLS in patients with arterial hypertension and unspecific neurologic symptoms. Moreover, the outcome is not favorable all the time and the association of D-WI with ADC can be an instrument capable of predicting irreversible lesions.
\end{abstract}

KEY WORDS: magnetic resonance imaging, leukoencephalopathy, arterial hypertension.

\begin{abstract}
Estudo da localização e evolução da leucoencefalopatia posterior reversível em crianças usando ressonância magnética

RESUMO - Objetivo: Avaliar a evolução e aspectos na ressonância magnética (RM) da leucoencefalopatia posterior reversível (LPR) em crianças. Método: Nove crianças com sintomas neurológicos e aumento súbito da pressão arterial foram estudadas por exame de RM encefálica. Resultados: Todas as crianças avaliadas tinham lesões vistas nas regiões parieto-occipitais em imagens ponderadas na seqüência FLAIR. Outras regiões também foram envolvidas. Quatro crianças apresentaram restrição na seqüência difusão e apenas duas com redução do coeficiente de difusão aparente (ADC), o qual evoluiu com lesões seqüelares em exame de controle; os outros pacientes tiveram regressão completa das lesões após terapia específica. Conclusão: A RM é um método importante para o diagnostico de LPR em pacientes com hipertensão arterial e sintomas neurológicos não específicos. Devido à evolução não ser favorável em todos os casos, a associação da difusão com ADC pode ser utilizada para predizer lesões irreversíveis.
\end{abstract}

PALAVRAS-CHAVE: ressonância magnética, leucoencefalopatia, hipertensão arterial.

Reversible posterior leukoencephalopathy syndrome (RPLS) is a disease with few cases reported in children. The main causes at this age are: the use of immunosuppressive drugs, arterial hypertension, vasculopathy and glomerulopathy ${ }^{1,2}$, but several other causes have also been associated to this disease ${ }^{3-6}$. RPLS is an entity that displays both clinical and radiologic aspects characterized by unspecific symptoms such as headache, vomiting, mental disorders, loss of vision, hypertension and seizures ${ }^{1,7,8}$. Because of its rarity, especially in children, a small number of physicians are familiar with RPLS and radiologists may play an important role in its diagnosis, and the establishment of treatment ${ }^{8}$. Magnetic resonance imaging (MRI) findings are typical with the features of the lesions better visualized on flair-weighted images, specifically of the posterior regions of the brain 9 . Occasionally the cerebellum, brainstem, basal ganglia and frontal lobes are involved. Paramedian and calcarine regions are often preserved which differentiates this disease from infarct ${ }^{1}$.

As the name suggests, this syndrome mainly affects the posterior regions of the brain, with only the white matter involved and normally completely rever-

Department of Radiology, Faculdade de Medicina Estadual de Rio Preto, Hospital de Base de São José do Rio Preto SP, Brazil (FAMERP): ${ }^{1} \mathrm{MD}$, Radiologist, Department of Radiology, FAMERP; ${ }^{2} \mathrm{MD}$, Resident of Radiology, FAMERP; ${ }^{3} \mathrm{MD}$, Pediatrician, FAMERP; ${ }^{4} \mathrm{MD}, \mathrm{PhD}$, Chief of the Department of Radiology, FAMERP.

Received 7 February 2006, received in final form 5 June 2006. Accepted 26 June 2006.

Dr. José Roberto Ferraz-Filho - Rua Brigadeiro Faria Lima 5544 - 15090-000 São José do Rio Preto SP - Brasil. E-mail: jrl.ferraz@ terra.com.br 
sible. Currently, due to the diversity of the presentation of RPLS, this name has become a misnomer for some authors ${ }^{4,10}$.

The purpose of our study is to evaluate clinical evolution and the MRI findings of RPLS in children.

\section{METHOD}

This study was approved by the Ethics Commitee and Research of FAMERP (Faculdade de Medicina de São José do Rio Preto).

Six female and three male patients, with ages ranging from 2 to 18 years (mean, 7 years), were prospectively studied. These children were evaluated using encephalic magnetic resonance performed by two experienced neuroradiologists in the Radiology Department of the Hospital de Base de São José do Rio Preto.

All patients were clinically examined by an experienced neuropediatric physician and presented with unspecified neurological signs including headache, vomiting, seizures, somnolence, visual disturbance, altered mental states, and arterial hypertension.

Brain MRI was performed with a $1.5 \mathrm{~T}$ super-conducting system (Gyroscan Intera, Philips Medical Systems, Best, the Netherlands) using a head coil. The protocol included axial FLAIR-weighted images [repetition time (TR)/echo time (TE)] $=6000 / 120 \mathrm{msec}$, field of view (FOV) 250x80, matrix 256x512, NSA 3, $5 \mathrm{~mm}$ slice thickness, gap of $1 \mathrm{~mm}$ ], axial turbo spin-echo T2-weighted images (TR/TE $=4466 / 110 \mathrm{msec}$, FOV 250x80, matrix size $400 \times 512$, NSA 2, $5 \mathrm{~mm}$ slice thickness, gap of $1 \mathrm{~mm}$ ) axial diffusion-weighted images (TR/TE= 1000/86 msec, FOV 230 x 100, matrix size 128x512, NSA 1, $5 \mathrm{~mm}$ slice thickness), axial, coronal and sagittal spin-echo T1-weighted, before and after paramagnetic contrast infusion (TR/TE=550/15 msec, FOV 230x85, matrix size 256x512, NSA 2, $5 \mathrm{~mm}$ slice thickness). Control examinations, using the same protocol, were performed only in three of the nine children (patients 1, 2 and 9) between two to six months after treatment for hypertension and/or reduction of the immunosuppressive drugs.

\section{RESULTS}

All results are summarized on Table.

All children suffered increases in the arterial blood pressure and seizures. Four patients did not show responses to verbal or pain stimuli and two presented with generalized edema. Two patients were taking high

Table. Patients' data.

\begin{tabular}{|c|c|c|c|c|c|c|}
\hline Patient & Age/gender & $\begin{array}{l}\text { Symptons } \\
\text { and signs }\end{array}$ & $\begin{array}{l}\text { Risk factor } \\
\text { for LPR }\end{array}$ & Location & $\begin{array}{l}\text { Diffusion/ } \\
\text { ADC }\end{array}$ & $\begin{array}{l}\text { Evolution/findings } \\
\text { on crontol MRI }\end{array}$ \\
\hline 1 & $3 / F$ & $\begin{array}{l}\text { amaurosis, } \\
\text { seizures }\end{array}$ & Hypertension & $\begin{array}{l}\text { Parietal, occipital and } \\
\text { frontal lobes (bilateral) } \\
\text { and thalami }\end{array}$ & $+/+$ & $\begin{array}{c}\text { Partial visual } \\
\text { loss/persistent lesions }\end{array}$ \\
\hline 2 & $5 / \mathrm{M}$ & $\begin{array}{l}\text { seizures, } \\
\text { headache }\end{array}$ & Hypertension & $\begin{array}{c}\text { Parietal and occipital } \\
\text { (bilateral), cerebelar and } \\
\text { frontal lobes (left) }\end{array}$ & $-/-$ & Resolved/ Resolved \\
\hline 3 & $18 / \mathrm{M}$ & seizures & Hypertension & $\begin{array}{l}\text { Parietal, occipital and } \\
\text { temporal lobes (bilateral), } \\
\text { brainstem, frontal lobe } \\
\text { (left) cerebellar (right) }\end{array}$ & $-/-$ & Resolved/ * \\
\hline 4 & $6 / F$ & seizures & Hypertension & $\begin{array}{l}\text { Occipital and parietal } \\
\text { lobes (bilateral) }\end{array}$ & $-/-$ & Resolved/ * \\
\hline 5 & $10 / \mathrm{F}$ & seizures & Hypertension & $\begin{array}{c}\text { Parietal and occipital } \\
\text { (bilateral) and thalami (left) }\end{array}$ & $+/-$ & Resolved/ * \\
\hline 6 & $11 / \mathrm{F}$ & seizures & Hypertension & $\begin{array}{l}\text { Parietal, occipital and } \\
\text { frontal (bilateral), } \\
\text { and thalami (left) }\end{array}$ & $+/-$ & Resolved/ * \\
\hline 7 & $7 / \mathrm{M}$ & seizures & Hypertension & $\begin{array}{l}\text { Parietal, occipital and } \\
\text { frontal lobes, cerebellum } \\
\text { (bilateral), thalami, left } \\
\text { medium cerebellar } \\
\text { penducle }\end{array}$ & $-/-$ & Resolved/ * \\
\hline 8 & $8 / F$ & seizures & Hypertension & $\begin{array}{l}\text { Parietal, occipital and } \\
\text { frontal (bilateral) }\end{array}$ & $-/-$ & Resolved/ * \\
\hline 9 & $5 / F$ & $\begin{array}{l}\text { seizures, } \\
\text { headache, } \\
\text { motor deficit } \\
\text { on ULM }\end{array}$ & Hypertension & $\begin{array}{l}\text { Parietal, occipital and } \\
\text { frontal (bilateral) }\end{array}$ & $+/+$ & $\begin{array}{l}\text { Partial motor } \\
\text { deficit/ persistent } \\
\text { parietal lesion } \\
\text { on FLAIR }\end{array}$ \\
\hline
\end{tabular}

M, male; F, female; LUL, left upper limb; +restriction on diffusion or reduced ADC; -normal diffusion or ADC; *no control MRI. 


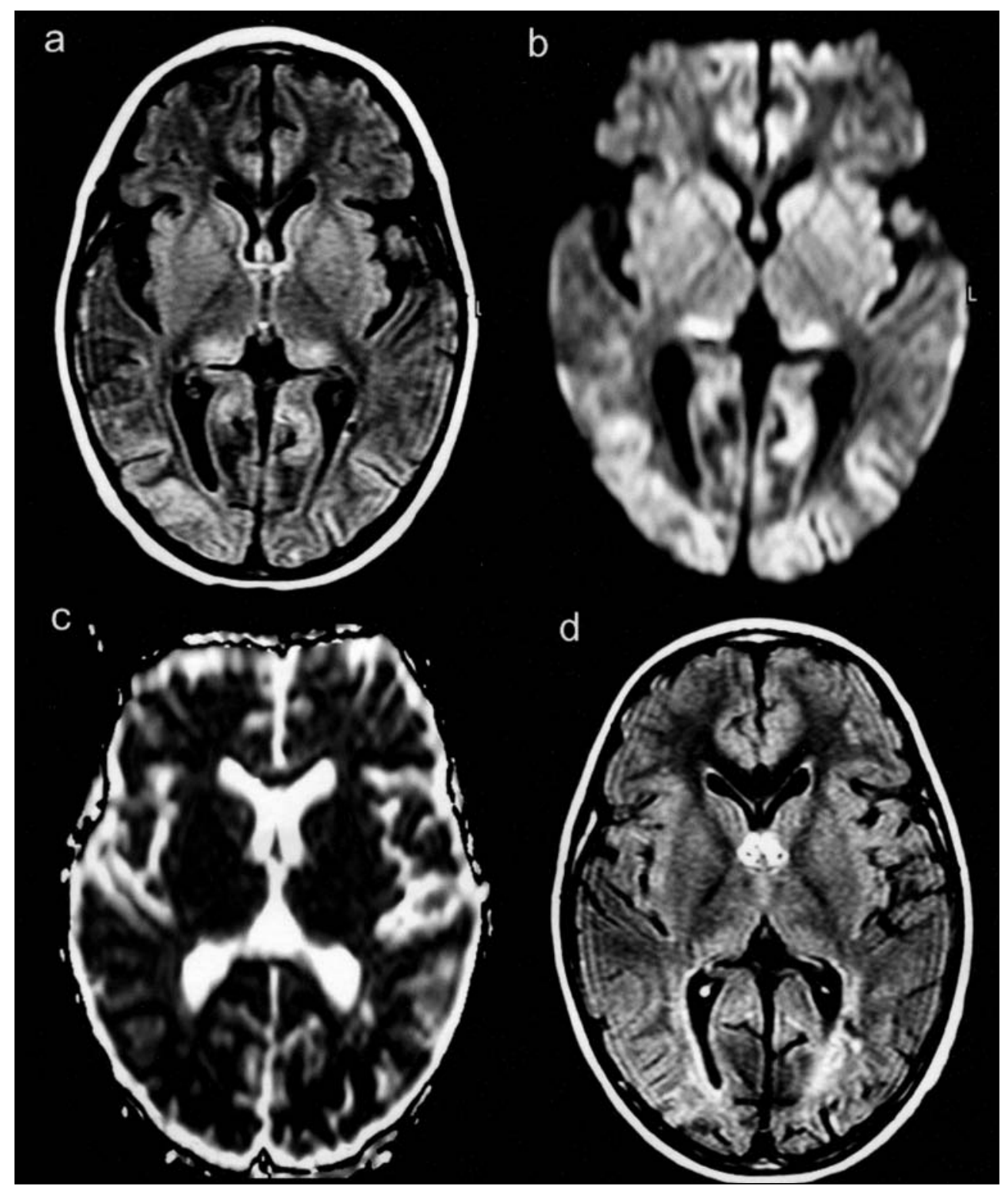

Fig 1. Patient 1: a) FLAIR-weighted image showing hyperintense lesions on parieto-occipital lobes and thalamus bilaterally. b) and c) Diffusion- weighted image showing restriction on the same regions and reduced ADC-map. d) FLAIR-weighted image of the control exam showing atrophy with residual lesions of the regions.

doses of cyclosporine. Two patients evolved with neurological sequela; one with partial loss of vision and the other with a motor deficit of the left upper limb.

In the MRI examinations, all the children had hypersignal in cortical and subcortical lesions seen on FLAIR images of the parietal-occipital regions (Figs 1 and 2). Other regions were also affected, including the frontal lobe in four children, the cerebellum in four, the thalamus in two, the corpus callosum in one and the temporal lobe in one. Of the nine patients, four presented with restriction in the diffusion sequence, two with reduction in the apparent diffu- sion coefficient ( $A D C$ ). These last two patients were evolved with sequela and persistence of the lesions seen on FLAIR images in control examinations two months after. The other seven patients had complete regression of the neurological states after anti-hypertensive therapy and/or reduction of the dose of immunosuppressive drugs. Three performed control MRI in which the symptoms had disappeared completely.

\section{DISCUSSION}

Recently, several studies have been trying to predict the evolution of RPLS $S^{8,11,12}$. Increased signal inten- 


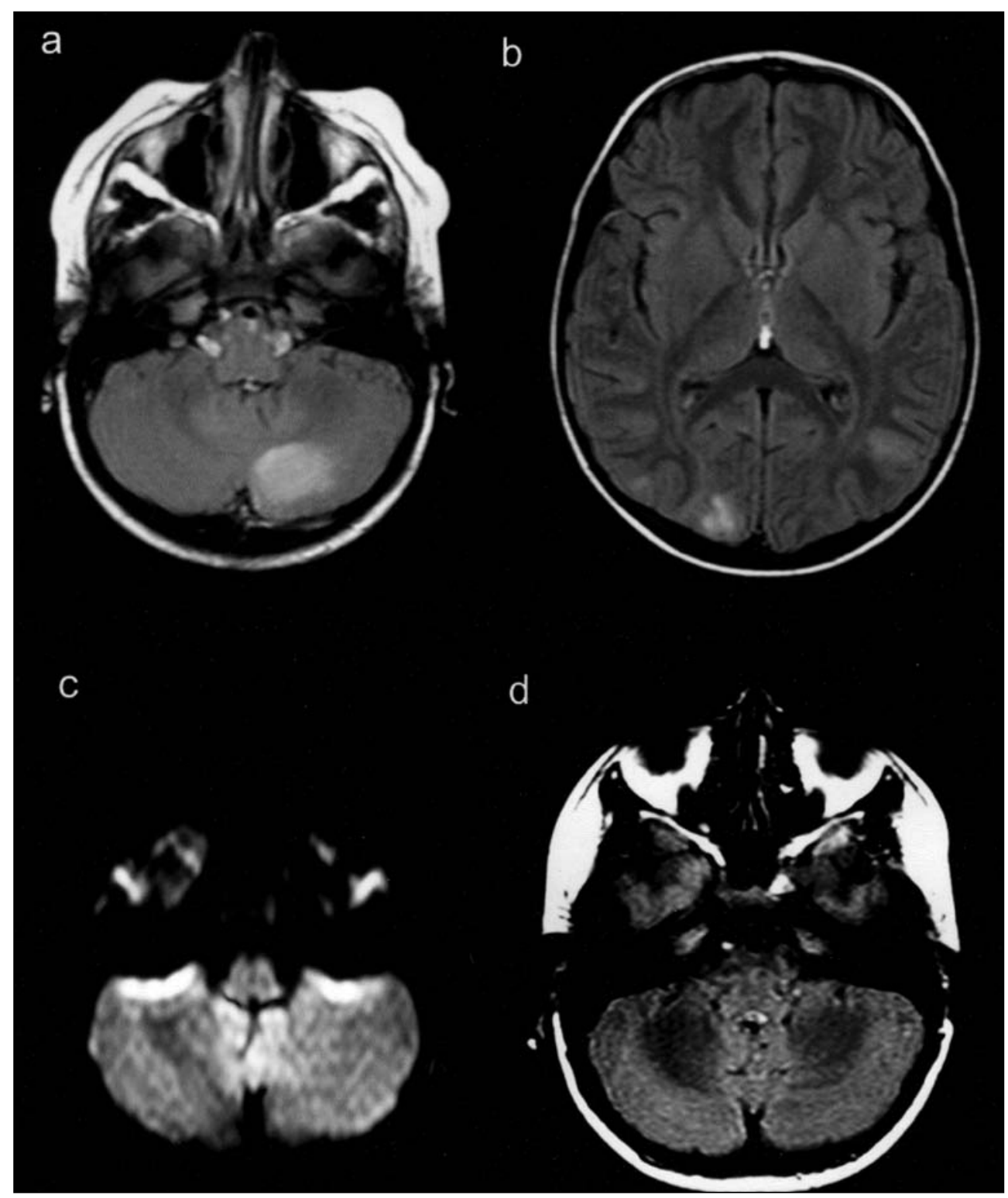

Fig 2. Patient 7: a) and b) FLAIR-weighted image showing hyperintense lesions on parieto-occipital lobes and left cerebellum. c) Diffusion- weighted image showing no restriction on the same regions (parieto-occipital lobes not shown). d) FLAIR-weighted image of the control exam showing no residual lesions.

sity on diffusion-weighted images (D-WI) with a decreased $A D C$, configure the illness as a result of cytotoxic edema, which can course with possible neurological sequela ${ }^{8,12}$. In our cases, four patients showed increased signal intensity on D-Wl; two of them did not show any reduction of the ADC and had a good outcome and the other two showed reduced ADC and had adverse outcomes. In the last two cases, persistent lesions were observed on control examinations. One suffered from partial loss of vision and the other suffered upper left limb motor deficit. The poor clinical prognosis related to the reduction of ADC, may be explained by the cytotoxic edema theory, characterized by an abrupt elevation of the blood pressure that induces a reflex vasoconstriction, leading to low blood flow and consequently cytotoxic edema and ischemia ${ }^{1,13}$. The reversibility of RPLS in the majority of cases diverges from cytotoxic edema theory $\mathbf{y}^{2,10}$.

Another acceptable theory is sustained by the abrupt elevation of the blood pressure with loss of autoregulation of the cerebral vessels, leading to a cerebral vasodilatation and vasogenic edema. When the average blood pressure (which normally ranges 
from 60 to $120 \mathrm{mmHg}$ ) increases, there is a tendency of vasoconstriction limiting the high blood flow and protecting the cerebral parenchyma, but sometimes the arterial blood pressure rises so high that regulation fails and plasma and cell extravasation occurs into the interstitial space both in the cortex and the white matter, which may explain the reversibility of some lesions and the vasogenic edema theory ${ }^{2,13}$.

Besides conventional MRI, proton spectroscopy and perfusion have been used to predict the evolution of RPLS ${ }^{7,13,14}$. Eicheler et al. ${ }^{14}$ analyzed proton spectroscopy in two patients with RPLS and showed rises of the choline level and a decrease in the $\mathrm{N}$-acetyl aspartate. Despite of these abnormalities, proton spectroscopy did not predict a bad prognosis. Sheth et al..$^{13}$ reported the use of perfusion in a study of ten patients taking cyclosporine but did not detect any subclinical abnormalities. We did not perform both proton spectroscopy and perfusion because these data were not the aim of this study.

In relation to the localization of the lesions in our study, all patients had hypersignal seen on FLAIRweighted images with cortical involvement particularly in the posterior regions of the brain. Concomitantly, were observed in order of frequency, lesions on the frontal lobe, cerebellum, thalami, corpus callosum and temporal lobes. These results are divergent from the first description of Hinchey et al. ${ }^{1}$, that reported this disease in 1996 after observing fifteen patients with lesions that mostly occurred in the parieto-occipital lobes affecting only the white matter, which when treated disappeared. The tendency of the involvement of the posterior regions of the brain was explained by the poor sympathetic innervation of the posterior circulation. Because of these aspects the syndrome was called posterior reversible leukoencephalopathy ${ }^{1,2}$.

RPLS can be also called atypical, due to the involvement of other regions of the brain besides the parieto-occipital lobe, like the majority cases of our study and concordant with other publications ${ }^{10,15,16}$. Because of this, sometimes it is difficult to differentiate RLPS from brain metabolic disorders such as anoxic encephalopathy and many other diseases which are normally induced by acute systemic arterial derangement ${ }^{9}$.

Supporting these recently described features that lesions can occur not only in the white matter as suggested by "leuko" 9 . Casey et al..${ }^{9}$ and Stott et al. ${ }^{10}$ proposed changing the name of RPLS to reversible posterior encephalopathy syndrome. Even so this name is still not completely appropriate for the disease due to the lack of irreversibility of the disease in some cases, as was seen in this study in $22 \%$ of cases.

Our experience in this study, showed that, the MRI findings of hyperintense lesions on FLAIR-weighted images with the predominantly posterior locations of the brain or not, were very important on the diagnosis of RPLS. The reason for these findings, was that in all the cases studied, the presentation was of unspecific neurological symptoms associated with arterial hypertension, situation that difficult the clinical diagnosis of this disease by the physicians.

In brief, our study show that, the MRI is important to suggest the diagnosis of RPLS in patients with hypertension and unspecific neurologic symptoms. Moreover, the outcome is not favorable all the time and the association of D-WI with ADC can be an instrument capable of predicting irreversible lesions that leads to neurological sequela.

\section{REFERENCES}

1. Hinchey J, Cahves C, Appignani, et al. A reversible posterior leukoencephalopathy syndrome. N Engl J Med 1996;334:494-497.

2. Lamy C, Oppenhein C, Meder JF, Mas JL. Neuroimaging in posterior reversible encephalopathy syndrome. J Neuroimaging 2004;141:89-96.

3. Kahana A, Rowley HA, Weinstein JM. Cortical blindness: clinical and radiologic findings in reversible posterior leukoencephalopathy syndrome: case report and review of the literature. Ophthalmology 2005; 112:7-11.

4. Ortega-Carnicer J, Ambros A, Diarte JI. Reversible posterior leukoencephalopathy syndrome in a young trauma patient. Resuscitation 2005; 64:119-120.

5. Kaito E, Terae S, Kobayashi R, Kudo K, Tha KK, Miyasaka K. The role of tumor lysis in reversible posterior leukoencephalopathy syndrome. Pediat Radiol 2005;35:722-727.

6. Obeid T, Shami A, Karsou S. The role of seizures in reversible posterior leukoencephalopathy. Seizure 2004;13;277-281.

7. Kwon S, Koo J, Lee S. Clinical spectrum of reversible posterior leukoencephalopathy syndrome. Pediat Neurol 2001;24:361-364.

8. Mukherjee P, McKinstry RC. Reversible posterior leukoencephalopathy syndrome: evaluation with diffusion-tensor MR imaging. Radiology 2001;219:756-765.

9. Casey SO, Sean O, Sampaio RC, Michel E, Truwit CL. Posterior reversible encephalopathy syndrome: utility of fluid-attenuated inversion recovery MR imaging in detection of cortical and subcortical lesions. AJNR 2000;21:1199-1206.

10. Stott Vl, Hurrel MA, Anderson TJ. Reversible posterior leukoencephalopathy syndrome: a misnomer reviewed. Intern Med J 2005; 35:83-89.

11. Prasad N, Gulati S, Gupta RK, Kumar R, Sharma RK. Is reversible posterior leukoencephalopathy with severe hypertension completely reversible in all patients? Pediat Nephrol 2003;18:1161-1166.

12. Covarrubias DJ, Luetmer PH, Norbert GC. Posterior reversible encephalopathy syndrome: prognostic utility of quantitative diffusion-weighed MR images. AJNR 2002;23:1038-1048.

13. Sheth NT, Ichise M, Kucharczyk W. Brain perfusion imaging in asymptomatic patients receiving cyclosporin. AJNR 1999;20:853-856.

14. Eicheler FS, Wang P, Wityk RJ, Beauchamp NJ Jr, Barker PB. Diffuse metabolic abnormalities in reversible posterior leukoecephalopaty syndrome. AJNR 2002;23:833-837.

15. Ahn KJ, You WJ, Jeong SL, et al. Atypical manifestations of reversible posterior leukoencephalopathy syndrome: findings on diffusion imaging and ADC mapping. Neuroradiology 2004;46:978-983.

16. Pavlakis SG, Frank Y,Kalina P, et al. Occipital-parietal encephalopathy: a new name for an old syndrome. Pediat Neurol 1997;16:145-148. 